\title{
Proximal Signaling Responses in Peripheral T Cells from Colorectal Cancer Patients are Affected by High Concentrations of Circulating Prostaglandin $\mathbf{E}_{2}$
}

\author{
Kristine Moltu $^{\mathrm{a}, \mathrm{b}}$, Karen Henjum ${ }^{\mathrm{b}, \mathrm{c}}$, Nikolaus G. Oberprieler ${ }^{\mathrm{b}}$, Bjørn A. Bjørnbeth ${ }^{\mathrm{c}}$ and $^{-}$ \\ Kjetil Taskén $^{\text {a,b,d,e,f,* }}$
}

${ }^{a}$ Centre for Molecular Medicine Norway (NCMM), Nordic EMBL Partnership, University of Oslo and Oslo University Hospital, P.O. Box 1137 Blindern, 0318 Oslo, Norway

${ }^{\mathbf{b}}$ Biotechnology Centre, University of Oslo, P.O. Box 1125 Blindern , 0317 Oslo, Norway

c Department of Gastrointestinal Surgery, Oslo University Hospital, P.O. Box 4956 Nydalen, 0424 Oslo, Norway

d Department of Infectious Diseases, Oslo University Hospital, , P.O. Box 4956 Nydalen, 0424 Oslo, Norway

e K.G. Jebsen Centre for Cancer Immunotherapy, Biotechnology Centre, University of Oslo, P.O. Box 1125 Blindern, 0317 Oslo, Norway

f K.G. Jebsen Inflammation Research Centre, Centre for Molecular Medicine Norway, University of Oslo, P.O. Box 1137 Blindern , 0318 Oslo, Norway

* Corresponding author:

Dr. Kjetil Taskén

Centre for Molecular Medicine

University of Oslo

P.O. Box 1125 Blindern

N-0317 Oslo, Norway

E-mail: kjetil.tasken@ncmm.uio.no

Phone: +47 22840505

Fax: $\quad+4722840506$

Short title: T-cell signaling profiles in colorectal cancer patients 
Abbreviations: BD; blood donors, CEA; carcinoembryonic antigen, COX; cyclooxygenase, CRC; colorectal cancer, ITAM; immunoreceptor tyrosine based activation motif, MFI; median fluorescence intensity, ND; not determined, NSAID; non-steroidal anti-inflammatory drug, Pat; patients, $\mathrm{PBMC}$; peripheral blood mononuclear cell, $\mathrm{PGE}_{2}$; prostaglandin $\mathrm{E}_{2}$, TCR; $\mathrm{T}$ cell receptor 


\begin{abstract}
Patients with colorectal cancer (CRC) have been shown to have elevated levels of circulating prostaglandin $\mathrm{E}_{2}\left(\mathrm{PGE}_{2}\right)$ which promotes cancer progression and suppresses T-cell immune responses. In this study we evaluated whether signaling responses in $\mathrm{T}$ lymphocytes obtained from peripheral blood of CRC patients were affected by the sustained exposure to increased levels of $\mathrm{PGE}_{2}$. The phosphorylation status of an extended panel of proteins involved in downstream signaling cascades in $\mathrm{T}$ cells was profiled at a single cell level both in naïve and antigen-experienced cells after triggering $\mathrm{T}$ cell-, prostaglandin- and interleukin-2 receptors. Peripheral $\mathrm{T}$ cells from patients with elevated $\mathrm{PGE}_{2}$ levels displayed aberrant $\mathrm{T}$-cell signaling responses downstream of the T cell receptor (assessed by reduced phospho-CD3 $\zeta$ and SLP76 responses), and after triggering the IL-2 receptor (assessed by reduced phosphorylation of STAT5) when compared to $\mathrm{T}$ cells from CRC patients with lower levels of $\mathrm{PGE}_{2}$ and $\mathrm{T}$ cells from healthy blood donors. This signaling study of circulating $\mathrm{T}$ cells from CRC patients indicates that increased systemic $\mathrm{PGE}_{2}$ levels affect proximal T-cell responses and confirm phospho-specific flow cytometry to be a valuable tool for revealing signaling signatures in immunological disorders.
\end{abstract}

Keywords: Colorectal cancer, $\mathrm{PGE}_{2}$, T cell signaling, phospho-specific flow cytometry 


\subsection{Introduction}

Colorectal cancer (CRC) is the third most commonly diagnosed cancer in the world [1] and with 42.2 and 36.1 new cases per 100,000 people per year for men and women, respectively, Norway is among the European countries with the highest incidence of CRC [2]. Most cases of CRC are sporadic and are thought to be driven by genetic mutations, epigenetic changes and chronic inflammation, as well as diet and lifestyle behaviors [3]. Colorectal cancer develops partly through adenomas and screening by colonoscopy is an effective, although costly, way to prevent CRC by identifying and removing pre-cancerous adenomas. In line with this, patients diagnosed with localized disease have an $80-90 \%$ five-year survival rate while the survival rate drops to under $10 \%$ for carcinomas with distant metastasis [4]. Surgery is the standard treatment for CRC that has not spread to distant sites, but patients with advanced and aggressive disease need adjuvant therapies, primarily involving chemoand radiation therapy which may considerably improve prognosis.

The host immune system is capable of mounting immune responses to the tumor cells, mainly through tumor infiltrating $\mathrm{T}$ lymphocytes and natural killer cells [5]. However, immune surveillance and activation are frequently ineffective in preventing or controlling tumor growth, and colorectal cancers have been shown to induce immune suppression linked to poorer clinical outcome [6]. Several mechanisms for immune suppression have been described, but the aberrant expression of cyclooxygenase-2 (COX-2) and its role in the production of prostaglandin $\mathrm{E}_{2}\left(\mathrm{PGE}_{2}\right)$ has a strong association with the development and maintenance of CRC [7]. Cyclooxygenase- 2 has been found to be overexpressed in $40 \%$ of colorectal adenomas [8] and in up to $90 \%$ of carcinomas [9]. Furthermore, we have previously revealed that $\mathrm{CRC}$ patients have elevated levels of circulating $\mathrm{PGE}_{2}$ in their blood [10]. The crucial role of COX-2 and $\mathrm{PGE}_{2}$ in $\mathrm{CRC}$ carcinogenesis is demonstrated by randomized trials proving regular pharmacological inhibition of the COX-enzymes with nonsteroidal anti-inflammatory drugs (NSAIDs) to be effective in reducing both the incidence and progression of intestinal tumors in CRC patients [11]. However, long-term use has been associated with side effects in the gastrointestinal tract and cardiovascular system which has dampened their use as chemopreventive agents. Additional modes of therapy and chemoprevention of CRC that are both effective and tolerable remain to be developed, and the $\mathrm{PGE}_{2}$ signaling pathway is a potential target which necessitates insight into the immunomodulatory role of $\mathrm{PGE}_{2}$ in $\mathrm{CRC}$ pathology. 
Cyclic adenosine monophosphate (cAMP) is the main intracellular second messenger of $\mathrm{PGE}_{2}$ and increased production of cAMP is known to inhibit TCR signaling through the protein kinase A (PKA) type I-CSK (COOH-terminal Src kinase)-LCK (lymphocyte-specific protein tyrosine kinase) signaling cascade [12]. The TCR complex lacks intrinsic enzymatic activity, but upon triggering of $\mathrm{T}$ cells, the tyrosine kinase LCK rapidly becomes activated and phosphorylates tyrosine residues within specialized motifs (immunoreceptor tyrosine based activation motifs; ITAMs) in the cytoplasmic tail of the signal transduction unit of the TCR/CD3 complex, the CD3 chains. Upon T-cell activation, PKA type I redistributes to and co-localizes with the TCR/CD3 complex [13] and phosphorylates its TCR proximal substrate CSK at serine 364, resulting in increased CSK activity [12]. CSK subsequently provides negative control of LCK by phosphorylating the inhibitory tyrosine 505 [14]. As a result, downstream T-cell signaling starting with ITAM phosphorylation of the CD3 chains is hindered. Prostaglandin $E_{2}$ exerts immune suppression on $T$ cells through multiple modes of action and has also been shown to inhibit the production of the pivotal $\mathrm{T}$ cell cytokine interleukin (IL)-2 [15], expression of the IL-2 receptor [16, 17] and IL-2 signal transduction elements [18] resulting in diminshed IL-2 stimulated proliferation responses.

The present study was designed to find out whether the levels of circulating $\mathrm{PGE}_{2}$ from the tumor and immune system in patients with CRC affect stimulation responses of peripheral $\mathrm{T}$ cells. Blood was drawn from patients not undergoing adjuvant therapy or receiving medication inflicting with prostaglandin synthesis and from healthy blood donors. We measured $\mathrm{PGE}_{2}$ levels and profiled signaling cascades in various $\mathrm{T}$ cell subsets after triggering T-cell-, prostaglandin- and interleukin-2 receptors in a phospho-specific flow cytometric setup.

\subsection{Materials and Methods}

\section{Patient material}

The study was approved by the Regional Committee for Medical Research Ethics, for SouthEastern Norway and conducted in compliance with the Declaration of Helsinki. Patients with colorectal cancer at the Department of Gastrointestinal Surgery, Oslo University Hospital, were enrolled in the study after obtaining written informed consent. 11 patients were enrolled in the study and ten of the patients were included in the final analysis (six women and four men; average age 67.2 years; range 37-90). Patients included were not medicated with steroids (inhibitors of arachidonic acid and prostaglandin synthesis), NSAIDs 
(inhibitors of COX-enzymes) and had not previously received chemo- or radiation therapy. Levels of carcinoembryonic antigen (CEA) were measured for six of the patients by ELISA (Roche, Basel, Switzerland) at the Department of Medical Biochemistry, Oslo University Hospital. Blood samples from five healthy blood donors (Blood Bank, Oslo University Hospital) were used as controls.

\subsubsection{Isolation and stimulation of cells}

Peripheral blood (approximately $50 \mathrm{ml}$ ) was drawn from patients pre-operatively. Peripheral blood mononuclear cells (PBMCs) $\left(24-100 \times 10^{6}\right.$ cells) from patients and blood donors were isolated by Isopaque-Ficoll (Lymphoprep, Axis-Shield PoC, Oslo, Norway) gradient centrifugation. Plasma was isolated from the samples and frozen at $-80{ }^{\circ} \mathrm{C}$ in order for $\mathrm{PGE}_{2}$ levels to be measured at the same time for all study objects. Cells were re-suspended in RPMI 1640 medium (Life Technologies, Carlsbad, CA, USA) supplemented with $1 \%$ fetal bovine serum, $1 \mathrm{mM}$ sodium pyruvate, $0.9 \%$ (v/v) MEM non-essential amino acids, $100 \mathrm{U} / \mathrm{ml}$ penicillin and $100 \mathrm{U} / \mathrm{ml}$ streptomycin for cell stimulation (all Life Technologies). Cells were subsequently left unstimulated or subjected to five different stimulation conditions at $37{ }^{\circ} \mathrm{C}$ (see Fig. 2A); (1) $\mathrm{PGE}_{2}(10 \mu \mathrm{M}$, Sigma-Aldrich, St. Louis, MO, USA) for $10 \mathrm{~min}$, (2) crosslinking of biotinylated anti-CD3 (1 $\mu \mathrm{g} / \mathrm{ml}$, clone OKT-3, custom affinity-purified and biotinylated by Diatec Monoclonals AS, Oslo, Norway) and biotinylated anti-CD28 (5 $\mu \mathrm{g} / \mathrm{ml}$, clone CD28.2, eBioscience, San Diego, CA, USA) with avidin (50 $\mu \mathrm{g} / \mathrm{ml}$, Zymed Laboratories, Life Technologies) for $1 \mathrm{~min}$, (3) a combination of $\mathrm{PGE}_{2}$ (10 $\mu \mathrm{M}, 10 \mathrm{~min}$ ) and TCR co-stimulation (anti-CD3/CD28, $1 \mathrm{~min}$ ), (4) IL-2 (100 IE, Sigma-Aldrich) for $30 \mathrm{~min}$ or (5) a combination of $\mathrm{PGE}_{2}(10 \mu \mathrm{M}, 40 \mathrm{~min})$ and IL-2 (100 IE, $\left.30 \mathrm{~min}\right)$.

\subsubsection{Prostaglandin $\mathrm{E}_{2}$ determination}

Peripheral blood from CRC patients as well as control samples were collected in EDTA vacuum tubes and centrifuged. Plasma was subsequently isolated and stored for 3-18 months at $-80{ }^{\circ} \mathrm{C}$, thawed and subsequently analyzed for PGE 2 levels by ELISA (R\&D, Minneapolis, MN, USA) according to manufacturer's description. All samples were analyzed simultaneously in duplets or triplicates. 


\subsubsection{Phospho-specific flow cytometric analysis}

Stimulation conditions were titrated as described in Kalland et al., 2011 [19] for antiCD3/CD28 co-stimulation and as described in Oberprieler et al., 2010 [20] for $\mathrm{PGE}_{2}$ treatment. After stimulation, cells were fixed immediately using pre-warmed formaldehyde (BD Phosflow Fix Buffer I, BD Biosciences, USA) for 10 min at $37^{\circ} \mathrm{C}$, permeabilized in methanol (BD Phosflow Perm Buffer III, BD Biosciences, San Jose, CA, USA) and stored at $-80{ }^{\circ} \mathrm{C}$. Cells from one patient and one control were then thawed and subjected to twodimensional fluorescence cell barcoding (FCB) with Pacific Blue and Alexa Fluor 488 or Pacific Orange (all Molecular Probes, Life Technologies), providing each sample with a unique fluorescent signature as described in Krutzik et al., 2006 [21]. Cells were washed and combined, and the pooled samples were stained with phospho-specific and surface marker antibodies for $30 \mathrm{~min}$ at room temperature. PerCP conjugated CD3, PE-Cy7 conjugated CD4 and PE conjugated CD45RO were all from BD Biosciences. All antibodies used to detect the phosphorylation status of the proteins were conjugated with Alexa Fluor 647. Antibodies

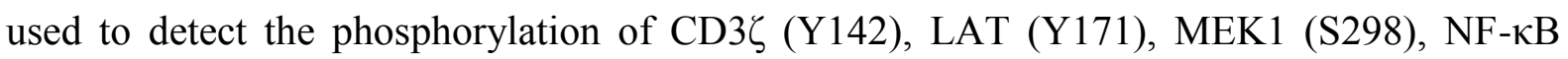
p65(S529), SAPK/JNK (T183/Y185), SLP76 (Y128), STAT1 (Y701), Rb (S807/S811), STAT1 (S727), STAT3 (Y705), STAT5 (Y694), ZAP70/Syk (Y319/Y352) and the isotype

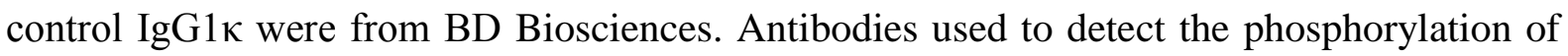
44/42 MAPK (T202/Y204), AKT (S473), AKT (T308), AKT substrate (RXRXXS/T), GSK3 $\alpha$ (S21), GSK3 $\beta$ (S9), histone H3 (S10), HSP27 (S78), MAPK substrate (PXTP), MAPKAPK-2 (T334), NF-кB p65 (S536), p38 MAPK (T180/Y182), PKA substrate (RRXS/T), S6-ribosomal protein (S235/S236), tyrosine (Y100), VASP (S157), VASP (S239) were from Cell Signaling Technology (Danvers, MA, USA). The antibody used to detect the phosphorylation of VAV1 (Y174) was from Santa Cruz Biotechnology (Dallas, TX, USA). Cells were washed and subsequently analyzed by flow cytometry with a FACSCanto II flow cytometer (BD Biosciences) equipped with $407 \mathrm{~nm}, 488 \mathrm{~nm}$ and $633 \mathrm{~nm}$ lasers. For fluorochrome compensation, PerCP conjugated CD3 antibody, PE-Cy7 conjugated CD4 antibody, PE-conjugated CD45RO antibody and Alexa Fluor 647 conjugated CD3 $\zeta$ antibody were added to compensation beads (CompBeads Compensation Particle Set, BD Biosciences), whereas aliquots of unstimulated cells were labeled with the highest concentrations of all fluorescent dyes as compensation controls for the fluorescent dyes. Unstimulated, non-FCB cells were used as reference for unstained cells. Compensation corrections for spectral overlap were automatically set using FACSDiva software (BD Biosciences). For each sample, 
at least 20,000 events from each cell population were recorded. Data were analyzed using the Cytobank program (https://www.cytobank.org/) and signaling responses were calculated as the fold change in median fluorescence intensity of treated versus unstimulated cells displayed on the arcsinh transformed ratio [see 21].

\subsubsection{Statistical analysis}

Data were analyzed using SigmaPlot 11.0 (Systat Software Inc., San Jose, CA, USA). Median values were compared with Mann-Whitney Rank Sum test and with Student T-test for pair-wise comparisons when normally distributed (Fig 3B). p $<0.05$ was considered significant.

\subsection{Results}

\subsubsection{Patient characteristics}

Eleven CRC patients were enrolled in the study, but one patient was excluded when the histopathological diagnosis was B cell lymphoma of the gut rather than CRC. Clinical characteristics of patients are presented in Table 1. TNM staging (T; tumor invasion, N; lymphatic node, $\mathrm{M}$; metastasis, combined with numbers from 0 to 4 indicating increasing severity) according to the American Joint Committee on Cancer showed that nine out of ten

patients were staged T3 or T4, meaning that the tumor had grown into the outermost layers of the colon or rectum or into organ structures. Half of the patients had spreading to regional lymph nodes whereas only one patient had distant metastasis. No correlation between $\mathrm{PGE}_{2}$ levels and number of positive lymph nodes or with levels of the tumor marker carcinoembryonic antigen (CEA) could be observed.

\subsubsection{Plasma concentrations of $\mathrm{PGE}_{2}$ and phenotypic characterization of $\mathrm{T}$ cell subsets}

Examining plasma concentrations of $\mathrm{PGE}_{2}$ it was clear that the patient group was not homogenous, but could be stratified into two groups, one with significantly higher plasma concentrations of $\mathrm{PGE}_{2}(n=6 ;>1000 \mathrm{pg} / \mathrm{ml})$ than the other $(n=4 ;<1000 \mathrm{pg} / \mathrm{ml})$ (Fig. $\left.1 \mathrm{~A}\right)$. Tcell signaling was therefore separately analyzed for each of these groups. Furthermore, $\mathrm{PGE}_{2}$ levels in the patient group with low levels of $\mathrm{PGE}_{2}$ were not significantly different from those of healthy blood donors that were included as controls (Fig. 1A). 
Activation of $\mathrm{T}$ lymphocytes occurs in lymphoid tissue and generates functionally diverse subsets of effector $\mathrm{T}$ cells that can be phenotypically distinguished by the expression of CD45RO. All patient and control samples were therefore subjected to flow cytometric analysis of their surface expression of CD4 and CD45RO for a more detailed subset analysis of $\mathrm{CD} 4$ and $\mathrm{CD} 8$ (identified as $\mathrm{CD}^{-}$) and $\mathrm{CD}^{-}$R5O ${ }^{-}$naïve $\mathrm{T}$ cells and $\mathrm{CD} 45 \mathrm{RO}^{+}$ effector/memory T cells (Fig. 1B). However, stratification on $\mathrm{PGE}_{2}$ levels did not reveal any differences in distribution of specific T cell subsets (Fig. 1C).

\subsubsection{Signal network mapping in CRC patient samples}

Earlier studies from our group have mapped $\mathrm{PGE}_{2}$ pathways in lymphoid cells from healthy individuals [20], which established a framework for analysis of $\mathrm{PGE}_{2}$ signaling in diseased cells. We therefore set out to map peripheral T-cell signaling responses in patients with CRC known to have elevated plasma levels of $\mathrm{PGE}_{2}$. Stimuli triggering T-cell responses; TCR costimulation, IL-2 or $\mathrm{PGE}_{2}$, in combination with surface markers and 30 phospho-epitope specific antibodies enabled a thorough phospho-specific flow cytometric analysis of downstream T-cell signaling cascades (Fig. 2A). A selection of the readouts for a representative $\mathrm{CRC}$ patient classified with low levels of circulating $\mathrm{PGE}_{2}$ are displayed in the heatmaps in Fig. 2B and 2C. Square color intensity represents fold change in median phosphorylation of stimulated cells relative to the level in unstimulated cells (arcsinh scale, a delta of 1.75 corresponds to a 10 -fold change). In parallel, the same protocol was applied to blood samples from healthy blood donors. Not all monitored phosphorylation parameters responded to the various treatments. Consequently, non-informative readouts were excluded from the rest of the analysis. T-cell signaling analysis from the CRC patient group as a whole versus blood donors did not reveal any significant signaling differences (data not shown). We therefore next stratified the group on $\mathrm{PGE}_{2}$ plasma concentrations, as accounted for in the previous section, into separate groups of samples from patients with low and high levels of $\mathrm{PGE}_{2}$. This enabled identification of $\mathrm{PGE}_{2}$ sensitive signaling nodes in $\mathrm{T}$ lymphocytes from CRC patients.

\subsubsection{Plasma levels of $\mathrm{PGE}_{2}$ affect proximal $\mathrm{T}$ cell receptor signaling events}

We found phosphorylation of $\mathrm{CD} 3 \zeta$ after one minute of TCR/CD28 co-stimulation to be significantly reduced in the CRC patient samples with elevated plasma levels of $\mathrm{PGE}_{2}$ when compared to CRC patient samples with lower levels of $\mathrm{PGE}_{2}$ and to samples obtained from 
healthy blood donors (Fig. 3A). The same tendency was observed in all $\mathrm{T}$ cell subsets investigated, although not significant for all comparisons. To test whether the cells were exhausted with respect to $\mathrm{PGE}_{2}$ responsiveness by endogenous stimuli, we also pre-incubated the cells with $10 \mu \mathrm{M}$ exogenous $\mathrm{PGE}_{2}$ prior to one minute of anti-CD3/CD28 co-stimulation. The phosphorylation of $\mathrm{CD} 3 \zeta$ was then compared pairwise to responses in the samples from the same individual without addition of $\mathrm{PGE}_{2}$ prior to TCR/CD28 co-stimulation. A significant reduction in phosphorylation of $\mathrm{CD} 3 \zeta$ was found in all samples (Fig. 3B).

A key signaling event following TCR stimulation is activation of the adaptor molecules LAT (linker for activation of T cells) and SLP76 (SH2 domain containing leukocyte phosphoprotein of $76 \mathrm{kDa}$ ). LAT and SLP76 create docking sites for other adaptors and signal relay molecules, thereby linking the TCR to downstream signaling events [23]. Phosphorylation of SLP76 clearly mirrored the results obtained for CD3 $\zeta$ (Fig. 3C) where CRC patient samples measured to have elevated $\mathrm{PGE}_{2}$ levels revealed reduced responses in

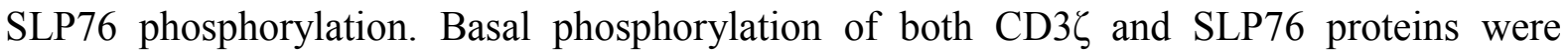
negligible in all subsets and for all groups of study participants (data not shown).

\subsubsection{The PKA signaling node of CRC patients with elevated plasma levels of $\mathrm{PGE}_{2}$ was not affected}

Activation of PKA by cAMP results in phosphorylation of nearby target substrates on serine or threonine residues presented in a preferred amino acid sequence context of argininearginine-X-serine/threonine (where $X$ denotes any amino acid) [24]. The anti-phospho PKA substrate antibody recognizes phosphorylated PKA substrates and was used to assess PKA activation in response to $\mathrm{PGE}_{2}$ treatment (Fig. 4A). We have previously reported maximum response for phosphorylation of PKA substrates to occur ten minutes after exposure to $10 \mu \mathrm{M}$ $\mathrm{PGE}_{2}$ [20] and this stimulation condition was therefore chosen for our study samples. However, we did not observe blunted responses in the PKA signaling node in CRC patient samples with higher $\mathrm{PGE}_{2}$ plasma levels. The levels of phosphorylation of direct targets of PKA such as VASP (vasodilator-stimulated phospho-protein) and GSK (glycogen synthase kinase) $3 \alpha$ (Fig. 4C and 4E, respectively) were neither affected. Variability among donor samples complicated conclusive readouts for the phospho-epitopes in the PKA signaling node.

When comparing basal phosphorylation levels of proteins in the PKA signaling node, the $\mathrm{CD}^{-} \mathrm{CD} 45 \mathrm{RO}^{+}$cells generally exhibited higher basal levels of activation than the other subsets (Fig. 4B, 4D and 4F). This observation has previously been reported from our group 
and was found to correlate with suppressed proximal TCR signaling [20], thus indicating that the PKA activity might prevent inappropriate activation of effector/memory cells.

Of note, stimulation with $\mathrm{PGE}_{2}$ alone did not directly affect the phosphorylation status of TCR proximal signaling molecules investigated in the present study (see Fig. 2B).

\subsubsection{Long-term exposure to $\mathrm{PGE}_{2}$ inhibits IL-2-specific phosphorylation of STAT5}

Signal disturbance caused by $\mathrm{PGE}_{2}$ on the IL-2 receptor pathway was tracked by IL-2induced phosphorylation of the transcription factor STAT5 (signal transducer and activator of transcription 5). T cells isolated from patients with increased levels of $\mathrm{PGE}_{2}$ responded more poorly to IL-2 treatment than T cells from control groups (Fig. 5A). Furthermore, we also analyzed evoked phospho-STAT5 responses after adding $\mathrm{PGE}_{2}$ on top of IL-2 stimulation, but found no apparent changes (data not shown). Another observation was the higher basal level of STAT5 phosphorylation in the $\mathrm{CD}^{-}$population (Fig. 5B).

\subsection{Discussion}

Prostaglandin $E_{2}$ is one of the most important biologically active prostaglandins found throughout the gastrointestinal tract [26] and promotes cell proliferation, angiogenesis, migration, tumor invasion and inhibition of apoptosis [27]. Consequently, $\mathrm{PGE}_{2}$ also influences on the carcinogenesis and progression of colorectal cancer. Our earlier studies revealed that elevated circulating levels of $\mathrm{PGE}_{2}$ are found in a proportion of patients with both primary and metastatic $\mathrm{CRC}[10,28]$ and that $\mathrm{PGE}_{2}$ levels take months to return to normal after surgery. The short half-life of $\mathrm{PGE}_{2}$ indicates that $\mathrm{COX}-2$ positive tumors are not the only source of $\mathrm{PGE}_{2}$, a significant part of the $\mathrm{PGE}_{2}$ production probably comes from inflammatory cells. Furthermore, we demonstrated that $\mathrm{PGE}_{2}$-mediated suppression of antitumor immune responses takes place both in primary and metastatic cancer and that the level of such suppression predicts clinical outcome [10, 28]. With this background, it was of interest to assess whether elevated $\mathrm{PGE}_{2}$ levels correlated with perturbed signaling downstream of the TCR and IL-2 receptor in peripheral T cells from CRC patients. Our present study supports the notion that $\mathrm{PGE}_{2}$ builds up an immunosuppressive network, also affecting the host at systemic levels.

Six out of ten CRC patient samples exhibited elevated $\mathrm{PGE}_{2}$ plasma levels (Fig. 1A). Dysregulated expression of COX-2 is considered the major determinant of $\mathrm{PGE}_{2}$ levels in 
CRC, but specific prostaglandin E synthases have like COX-2 been found to be up-regulated in colorectal tumors [29]. Enzymes catalyzing degradation of prostaglandins are less evaluated in relationship to tumor progression, but loss of 15-hydroxyprostaglandin dehydrogenase (15-PGDH) has been reported in colorectal tumors [30]. A role for differential expression of the four $\mathrm{PGE}_{2}$ receptors (EP1-4) during human colorectal tumorigenesis has also been implied. Colorectal cancer cells and their neighbor cells have been shown to have augmented expression of receptors EP2 [31] and EP4 [32] that stimulate cAMP production upon activation, whereas the EP3 receptor expression, known to inhibit cAMP production upon activation, is often lowered in target cells [33]. Collectively, these data reflect that the impact of $\mathrm{PGE}_{2}$ in $\mathrm{CRC}$ pathogenesis is caused by an imbalance in $\mathrm{PGE}_{2}$ synthesis and turnover and in the pattern of receptor expression.

The most profound signaling differences in the present study were found in the phosphorylation of $\mathrm{CD} 3 \zeta$ after one minute of TCR/CD28 co-stimulation, elevated plasma

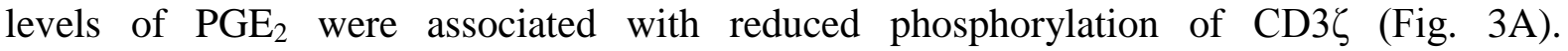
Prostaglandin $\mathrm{E}_{2}$ signals mainly in a cAMP-dependent fashion in $\mathrm{T}$ cells and inhibits TCR signaling through the PKA type I-CSK-LCK pathway [12, 14]. Since phosphorylation of $\mathrm{CD} 3 \zeta$ in all samples were responsive to the addition of exogenous $\mathrm{PGE}_{2}$, independent of the endogenous levels of $\mathrm{PGE}_{2}$, the inhibitory pathway did not seem to be fully desensitized in any population. Immune dysfunction in T cells from CRC patients and tumor-bearing mice have otherwise previously been suggested to be caused by loss of key signaling molecules

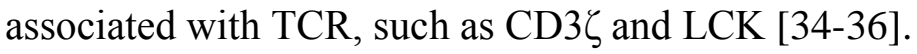

Prostaglandin $E_{2}$ acts as a second messenger related to G-protein coupled receptors and in response to repeated or long-lasting stimuli, second messenger signals are often dampened due to negative feedback loops or desensitization mechanisms [37]. Downregulation of $\mathrm{EP}$ receptors or $\mathrm{PGE}_{2}$ signaling elements after prolonged exposure of $\mathrm{PGE}_{2}$ could therefore be a plausible explanation for the non-conclusive readouts in $\mathrm{PGE}_{2}$ signaling targets (Fig. 4).

Interleukin- 2 is a potent $\mathrm{T}$ cell mitogenic stimulus and has been exploited as a means to boost immune responses to cancer, but has shown no clinical benefit in CRC [38]. Our study is in agreement with accumulated evidence from several groups indicating that increased PGE 2 levels exert negative control on IL-2 stimulated responses, assessed by IL-2induced activation of STAT5 (Fig. 5A) [15-18, 39]. The IL-2 receptor functions as a heterotrimer and the high affinity IL-2R contains all three subunits, IL-2R $\alpha, \beta$ and the common $\gamma \mathrm{c}$. Expression and dimerization of the $\beta$ and $\gamma \mathrm{c}$ chains alone are sufficient to 
mediate IL-2 dependent signaling [40]. We found IL-2 to induce higher phosphorylation responses of phospho-STAT5 in the memory compartment. This can be explained by their constitutive expression of both IL2-R $\beta$ and $\gamma c$, contrary to naïve cells which require activation-induced up-regulation of the $\beta$ chain [41].

In conclusion, despite a small sample size we found that proximal T-cell phosphorylation cascades were blunted in CRC patient samples with elevated $\mathrm{PGE}_{2}$ levels. Our findings thereby add to previous results on $\mathrm{PGE}_{2}$ as a negative regulator of $\mathrm{T}$-cell signaling and a key mediator of immunopathology in cancer. However, PGE $_{2}$-regulated networks are likely to act in concert with other important signaling pathways not investigated in this study that become dysregulated in CRC. Furthermore, we confirmed phospho-specific flow cytometry to be a valuable tool for revealing specific signaling signatures of T-cell activation that could reflect regulation of anti-tumor immunity in CRC.

\subsection{Author Contributions}

Conceived and designed the experiments: NGO BAB KT. Performed the experiments: KM KH NGO. Analyzed the data: KM KT. Contributed reagents/materials/analysis tools: BAB KT. Wrote the paper: KM KT. Critically reviewed the final manuscript: All authors. 


\subsection{References}

1. WHO GLOBOCAN 2012: Estimated Cancer Incidence, Mortality and Prevalence Worldwide in 2012. 2012; Available: http://globocan.iarc.fr/Pages/fact_sheets_ cancer.aspx. Accessed 14 November 2013.

2. Norwegian Cancer Registry. Cancer Statistics. 2011; Available: http://www.kreftregisteret.no/no/registrene/kreftstatistikk/. Accessed 14 November 2013.

3. Wang D, DuBois RN. The role of anti-inflammatory drugs in colorectal cancer. Annu Rev Med. 2013;64: 131-144.

4. National Cancer Institute. SEER Stat Fact Sheets: Colon and Rectum Cancer. 2009; Available: http://seer.cancer.gov/statfacts/html/all.html. Accessed 14 November 2013.

5. Waldner M, Schimanski CC, Neurath MF. Colon cancer and the immune system: the role of tumor invading T cells. World J Gastroenterol. 2006;12: 7233-7238.

6. Evans C, Dalgleish AG, Kumar D Review article: immune suppression and colorectal cancer. Aliment Pharmacol Ther. 2006;24: 1163-1177.

7. Sinicrope FA, Gill S. Role of cyclooxygenase-2 in colorectal cancer. Cancer Metastasis Rev. 2004;23: 63-75.

8. Eberhart CE, Coffey RJ, Radhika A, Giardiello FM, Ferrenbach S, et al. Up-regulation of cyclooxygenase 2 gene expression in human colorectal adenomas and adenocarcinomas. Gastroenterology 1994;107: 1183-1188.

9. Ogino S, Kirkner GJ, Nosho K, Irahara N, Kure S, et al. Cyclooxygenase-2 expression is an independent predictor of poor prognosis in colon cancer. Clin Cancer Res. 2008;14: $8221-8227$.

10. Yaqub S, Henjum K, Mahic M, Jahnsen FL, Aandahl EM, et al. Regulatory T cells in colorectal cancer patients suppress anti-tumor immune activity in a COX-2 dependent manner. Cancer Immunol Immunother. 2008;57: 813-821.

11. Rothwell PM, Wilson M, Elwin CE, Norrving B, Algra A, et al. Long-term effect of aspirin on colorectal cancer incidence and mortality: 20-year follow-up of five randomised trials. Lancet. 2010;376: 1741-1750.

12. Vang T, Torgersen KM, Sundvold V, Saxena M, Levy FO, et al. Activation of the $\mathrm{COOH}$-terminal Src kinase (Csk) by cAMP-dependent protein kinase inhibits signaling through the T cell receptor. J Exp Med . 2001;193: 497-507. 
13. Skålhegg BS, Taskén K, Hansson V, Huitfeldt HS, Jahnsen T, et al. Location of cAMPDependent Protein Kinase type I with the TCR-CD3 Complex. Science. 1994;263: 8487.

14. Bergman M, Mustelin T, Oetken C, Partanen J, Flint NA, et al. The human p50csk tyrosine kinase phosphorylates p561ck at Tyr-505 and down regulates its catalytic activity. EMBO J. 1992;11: 2919-2924.

15. Mary D, Aussel C, Ferrua B, Fehlmann M. Regulation of interleukin 2 synthesis by cAMP in human T cells. J Immunol. 1987;139: 1179-1184.

16. Anastassiou ED, Paliogianni F, Balow JP, Yamada H, Boumpas DT. Prostaglandin E2 and other cyclic AMP-elevating agents modulate IL-2 and IL-2R alpha gene expression at multiple levels. J Immunol. 1992;148: 2845-2852.

17. Rincon M, Tugores A, Lopez-Rivas A, Silva A, Alonso M, et al. Prostaglandin E2 and the increase of intracellular cAMP inhibit the expression of interleukin 2 receptors in human T cells. Eur J Immunol. 1988;18: 1791-1796.

18. Kolenko V, Rayman P, Roy B, Cathcart MK, O'Shea J, et al. Downregulation of JAK3 protein levels in $\mathrm{T}$ lymphocytes by prostaglandin $\mathrm{E} 2$ and other cyclic adenosine monophosphate-elevating agents: impact on interleukin-2 receptor signaling pathway. Blood. 1999;93: 2308-2318.

19. Kalland ME, Oberprieler NG, Vang T, Tasken K, Torgersen KM. T cell-signaling network analysis reveals distinct differences between CD28 and CD2 costimulation responses in various subsets and in the MAPK pathway between resting and activated regulatory T cells. J Immunol. 2011;187: 5233-5245.

20. Oberprieler NG, Lemeer S, Kalland ME, Torgersen KM, Heck AJ, et al. Highresolution mapping of prostaglandin E2-dependent signaling networks identifies a constitutively active PKA signaling node in CD8+CD45RO+ T cells. Blood. 2010;116: 2253-2265.

21. Krutzik PO, Nolan GP. Fluorescent cell barcoding in flow cytometry allows highthroughput drug screening and signaling profiling. Nat Methods. 2006;3: 361-368.

22. Irish JM, Myklebust JH, Alizadeh AA, Houot R, Sharman JP, et al. B-cell signaling networks reveal a negative prognostic human lymphoma cell subset that emerges during tumor progression. Proc Natl Acad Sci U S A. 2010;107: 12747-12754.

23. Torgersen KM, Aandahl EM, Taskén K. Molecular architecture of signal complexes regulating immune cell function. Handb Exp Pharmacol. 2008;186: 327-364. 
24. Shabb JB. Physiological substrates of cAMP-dependent protein kinase. Chem Rev. 2001;101: 2381-2411.

25. Butt E, Abel K, Krieger M, Palm D, Hoppe V, et al. cAMP- and cGMP-dependent protein kinase phosphorylation sites of the focal adhesion vasodilator-stimulated phosphoprotein (VASP) in vitro and in intact human platelets. J Biol Chem. 1994;269: $14509-14517$.

26. Dey I, Lejeune M, Chadee K. Prostaglandin E2 receptor distribution and function in the gastrointestinal tract. Br J Pharmacol. 2006;149: 611-623.

27. Chell S, Kaidi A, Williams AC, Paraskeva C. Mediators of PGE2 synthesis and signalling downstream of COX-2 represent potential targets for the prevention/treatment of colorectal cancer. Biochim Biophys Acta. 2006;1766: 104-119.

28. Brudvik KW, Henjum K, Aandahl EM, Bjornbeth BA, Taskén K. Regulatory T-cellmediated inhibition of antitumor immune responses is associated with clinical outcome in patients with liver metastasis from colorectal cancer. Cancer Immunol Immunother. 2012;61: 1045-1053.

29. Yoshimatsu K, Golijanin D, Paty PB, Soslow RA, Jakobsson PJ, et al. Inducible microsomal prostaglandin E synthase is overexpressed in colorectal adenomas and cancer. Clin Cancer Res. 2001;7: 3971-3976.

30. Backlund MG, Mann JR, Holla VR, Buchanan FG, Tai HH, et al. 15Hydroxyprostaglandin dehydrogenase is down-regulated in colorectal cancer. J Biol Chem. 2005;280: 3217-3223.

31. Sonoshita M, Takaku K, Sasaki N, Sugimoto Y, Ushikubi F, et al. Acceleration of intestinal polyposis through prostaglandin receptor EP2 in Apc(Delta 716) knockout mice. Nat Med. 2001;7: 1048-1051.

32. Chell SD, Witherden IR, Dobson RR, Moorghen M, Herman AA, et al. Increased EP4 receptor expression in colorectal cancer progression promotes cell growth and anchorage independence. Cancer Res. 2006;66: 3106-3113.

33. Shoji Y, Takahashi M, Kitamura T, Watanabe K, Kawamori T, et al. Downregulation of prostaglandin E receptor subtype EP3 during colon cancer development. Gut. 2004;53: $1151-1158$

34. Matsuda M, Petersson M, Lenkei R, Taupin JL, Magnusson I, et al. Alterations in the signal-transducing molecules of $\mathrm{T}$ cells and NK cells in colorectal tumor-infiltrating, gut mucosal and peripheral lymphocytes: correlation with the stage of the disease. Int $\mathbf{J}$ Cancer. 1995;61: 765-772. 
35. Mizoguchi H, O'Shea JJ, Longo DL, Loeffler CM, McVicar DW, et al. Alterations in signal transduction molecules in $\mathrm{T}$ lymphocytes from tumor-bearing mice. Science. 1992;258: 1795-1798.

36. Nakagomi H, Petersson M, Magnusson I, Juhlin C, Matsuda M, et al. Decreased expression of the signal-transducing zeta chains in tumor-infiltrating T-cells and NK cells of patients with colorectal carcinoma. Cancer Res. 1993; 53: 5610-5612.

37. Lohse MJ. Molecular mechanisms of membrane receptor desensitization. Biochim Biophys Acta. 1993;1179: 171-188.

38. Grande C, Firvida JL, Navas V, Casal J. Interleukin-2 for the treatment of solid tumors other than melanoma and renal cell carcinoma. Anticancer Drugs. 2006; 17: 1-12.

39. Zhang H, Conrad DM, Butler JJ, Zhao C, Blay J, et al. Adenosine acts through A2 receptors to inhibit IL-2-induced tyrosine phosphorylation of STAT5 in T lymphocytes: role of cyclic adenosine 3', 5'-monophosphate and phosphatases. J Immunol. 2004;173: 932-944.

40. Nakamura Y, Russell SM, Mess SA, Friedmann M, Erdos M, et al. Heterodimerization of the IL-2 receptor beta- and gamma-chain cytoplasmic domains is required for signalling. Nature. 1994;369: 330-333.

41. Malek TR and Castro I. Interleukin-2 receptor signaling: at the interface between tolerance and immunity. Immunity. 2010;33: 153-165. 


\section{Table Legend}

Table 1. Patient characteristics. Clinical, histopathological and laboratory data on the ten CRC patients included in the data analysis. CEA; carcinoembryonic antigen, ND; not determined. 


\section{Figure Legends}

Figure 1. Levels of circulating $\mathrm{PGE}_{2}$ and phenotypical characterization of $\mathbf{T}$ cell subsets in the study population. A) Levels of $\mathrm{PGE}_{2}(\mathrm{pg} / \mathrm{ml})$ were measured in plasma from patients (Pat) with CRC prior to surgery $(n=10)$ and healthy blood donors (BD) $(n=5)$. Freshly isolated plasma was frozen at $-80{ }^{\circ} \mathrm{C}$ before $\mathrm{PGE}_{2}$ was analyzed by ELISA. The study population was subsequently stratified on levels of $\mathrm{PGE}_{2}$ into groups with low (Pat $\mathrm{PGE}_{2}$ low) and high $\mathrm{PGE}_{2}$ (Pat $\mathrm{PGE}_{2}$ high) levels as indicated for each boxplot. $\mathrm{p}<0.01$, Mann-Whitney Rank Sum test. B) Gating strategy of the T cell subsets. First, a FSC/SSC plot was made and lymphocytes were identified. The lymphocyte gate was copied to a SSC/CD3 plot identifying $\mathrm{CD}^{+}$lymphocytes. Then, the $\mathrm{CD}^{+}$lymphocyte gate was copied to a CD4/CD45RO plot that identified $\mathrm{CD}^{+}$and $\mathrm{CD}^{-}$naïve $\left(\mathrm{CD} 45 \mathrm{RO}^{-}\right)$and effector/memory $\left(\mathrm{CD} 45 \mathrm{RO}^{+}\right)$cells. C) After isolation of peripheral blood mononuclear cells (PBMCs), $\mathrm{CD}^{+}$lymphocytes from the study participants were phenotypically characterized based on their surface expression of CD4 and CD45RO molecules. Mean \pm SEM is shown.

Figure 2. Phospho-specific signaling profiles of peripheral T cells from CRC patients. A) Workflow of the phospho-specific flow cytometric analysis. Blood was drawn from CRC patients before surgery $(n=10)$, PBMCs were isolated and samples were split into various stimulation conditions regulating $\mathrm{T}$ cell responses. Following stimulation, cells were fixed with formaldehyde and subjected to two-dimensional barcoding with increasing concentrations of amino-reactive dyes which allowed pooling of the samples. Cells were then permeabilized with methanol for gaining access to intracellular phospho-epitopes of a range of proteins. Signaling responses were measured by flow cytometric analysis. B) Heatmap depicting phospho-specific responses for a selection of the proteins included in the analysis of the $\mathrm{CD}^{+}$population from a CRC patient with non-elevated (low) levels of $\mathrm{PGE}_{2}$. Heatmap is colored according to the change in median fluorescence intensity (MFI) of stimulated relative to unstimulated samples on the archsinh scale (annotated as arcsinh median

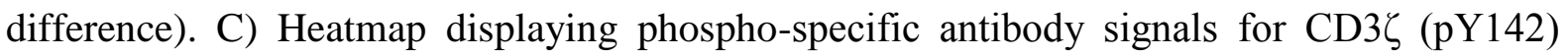
(upper panel) and PKA substrates (RRXpS/pT) (lower panel) in various T cell subsets.

Figure 3. Aberrant proximal $T$ cell receptor signaling in CRC patients with increased levels of circulating PGE 2 . A) Phosphorylation of the CD3 $\zeta$ chain (pY142) after one minute 
of $\mathrm{CD} 3 / \mathrm{CD} 28$ co-stimulation of $\mathrm{T}$ cells from CRC patients with high levels of circulating $\mathrm{PGE}_{2}(n=6)$ compared to $\mathrm{T}$ cells from patients with low levels of $\mathrm{PGE}_{2}(n=4)$, to healthy blood donors $(n=5)$ and to the total population with low $\mathrm{PGE}_{2}$ levels $(n=9)$. Cells were incubated with biotinylated anti-CD3 (OKT3, $1 \mu \mathrm{g} / \mathrm{ml})$ and anti-CD28 (CD28.2, $5 \mu \mathrm{g} / \mathrm{ml})$ before subsequent cross-linking with avidin $(50 \mu \mathrm{g} / \mathrm{ml})$ for one minute. Responses of the stimulated sample were compared to the unstimulated sample within each subpopulation. Mean \pm SEM is shown. * $\mathrm{p}<0.05$, \# $\mathrm{p}<0.01$ (Mann-Whitney Rank Sum test). B) Percentage of reduction in phosphorylation of $\mathrm{CD} 3 \zeta$ (pY142) in all T cell subsets when adding $10 \mu \mathrm{M}$ exogenous $\mathrm{PGE}_{2}$ prior to one minute of $\mathrm{CD} 3 / \mathrm{CD} 28$ co-stimulation compared to phosphorylation of CD3 $\zeta$ (pY142) in A. Mean \pm SEM is shown. One minute of anti-

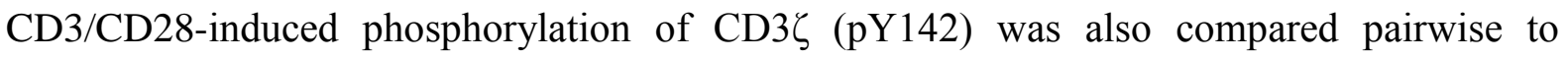
responses in the same samples pre-incubated for ten minutes with $10 \mu \mathrm{M}$ exogenous $\mathrm{PGE}_{2}$ prior to $\mathrm{CD} 3 / \mathrm{CD} 28$ co-stimulation. $\not \mathrm{p}<0.05$ (paired t-test). C) Cells were analyzed for SLP76 phosphorylation (pY128) as in A. Mean \pm SEM is shown. Pat; patients, BD; blood donors.

Figure 4. Plasma levels of $\mathrm{PGE}_{2}$ in CRC patients do not affect PKA signaling in peripheral T cells. A, C, E) Levels of PKA substrate (RRXpS/pT), VASP (pS157) and GSK3 $\alpha$ (pS21) phosphorylation after ten minutes incubation with exogenous $\operatorname{PGE}_{2}(10 \mu \mathrm{M})$ in $\mathrm{T}$ cells from CRC patients with high levels of circulating $\mathrm{PGE}_{2}(n=6)$ compared to patients with low levels of $\mathrm{PGE}_{2}(n=4)$, to healthy blood donors $(n=5)$ and to the total population with low $\mathrm{PGE}_{2}$ levels $(n=9)$. Responses of stimulated sample were compared to unstimulated sample within each subpopulation. Mean \pm SEM is shown. B, D, F) Basal levels of phosphorylation of PKA substrates (RRXpS/pT), VASP (pS157) and GSK $\alpha(\mathrm{pS} 21)$ in T cell subsets compared to the $\mathrm{CD}^{+} \mathrm{CD}^{+} 5 \mathrm{RO}^{-}$population. Mean $\pm \mathrm{SEM}$ is shown. Pat; patients, BD; blood donors.

Figure 5. Abrogated IL-2-induced STAT5 phosphorylation in CRC patient samples with high levels of circulating PGE $_{2}$. A) STAT5 (pY694) phosphorylation after IL-2stimulation (100 IE, $30 \mathrm{~min}$ ) in T cells from CRC patients with high $(n=6)$ and low $(n=4)$ levels of circulating $\mathrm{PGE}_{2}$, healthy blood donors $(n=5)$ and to the total population with low $\mathrm{PGE}_{2}$ levels ( $\left.n=9\right)$. Response of stimulated sample was compared to unstimulated sample within each subpopulation. Mean \pm SEM is shown. ${ }^{*} \mathrm{p}<0.05$. B) Basal levels of STAT5 
(pY694) in T cell subsets when compared to the $\mathrm{CD}^{+}{ }^{+} \mathrm{CD} 45 \mathrm{RO}^{-}$population. Mean $\pm \mathrm{SEM}$ is shown. Pat; patients, BD; blood donors. 


\begin{tabular}{ccllcrr} 
Sex & Age & Primary focus & TNM & $\begin{array}{c}\text { \# of positive } \\
\text { lymph nodes }\end{array}$ & $\begin{array}{c}\text { CEA } \\
(\boldsymbol{\mu g} / \mathbf{l})\end{array}$ & $\begin{array}{c}\text { PGE } \\
(\mathbf{p g} / \mathbf{m l})\end{array}$ \\
\hline F & 37 & colon sigmoideum & T3N1M0 & 2 & 0.9 & 1211 \\
F & 64 & colon ascendens & T4N0M0 & 0 & 2.5 & 801 \\
F & 72 & colon ascendens & T3N1M0 & 3 & 2.3 & 1124 \\
F & 80 & colon ascendens & T3N2M1 (oment) & 6 & 10.5 & 802 \\
F & 86 & rectum & T3N0M0 & 0 & ND & 865 \\
F & 90 & coecum & T3N0M0 & 0 & ND & 1320 \\
M & 43 & coecum & T3N0M0 & 0 & ND & 1129 \\
M & 57 & rectum & T3N1M0 & 4 & 1.0 & 1177 \\
M & 71 & colon sigmoideum & T3N1M0 & 1 & ND & 883 \\
M & 72 & colon transversum & T2N0M0 & 0 & 3.3 & 1399 \\
\hline
\end{tabular}




\section{Figure 1}

Click here to download high resolution image
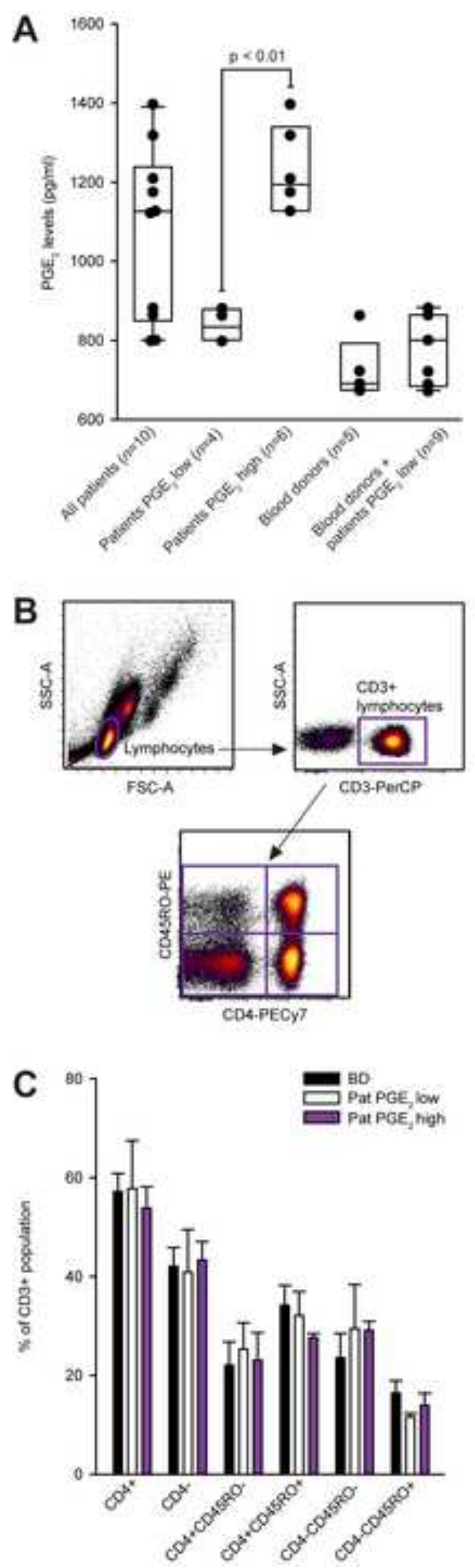
Click here to download high resolution image<smiles>[3H]C[C@H]1C[C@@H]1C</smiles>

Draw blood, isolate PBMC

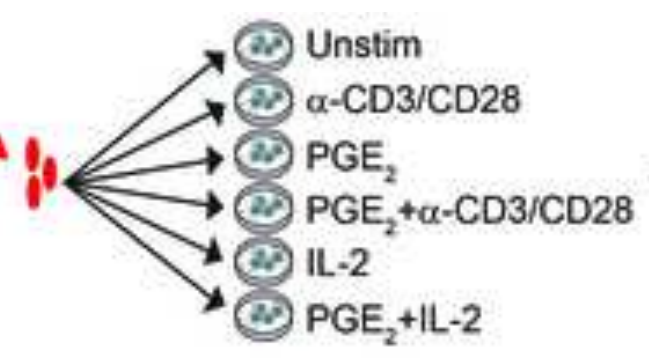

Split sample for stimulation

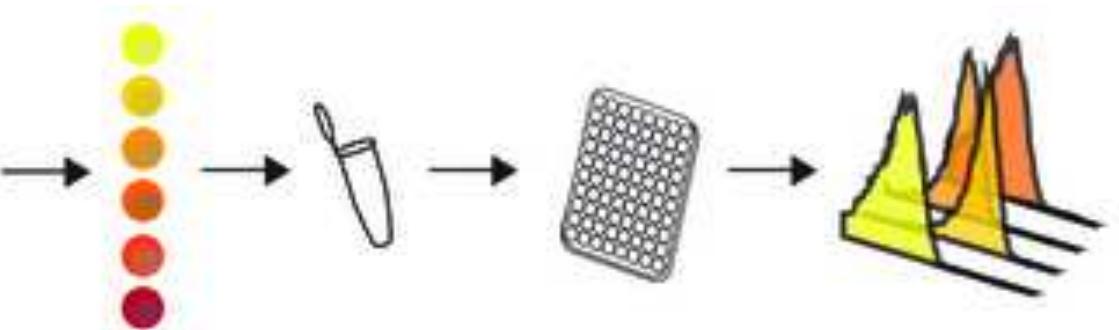

Fix and barcode
Combine
and perm

Run flow and analyze data

B

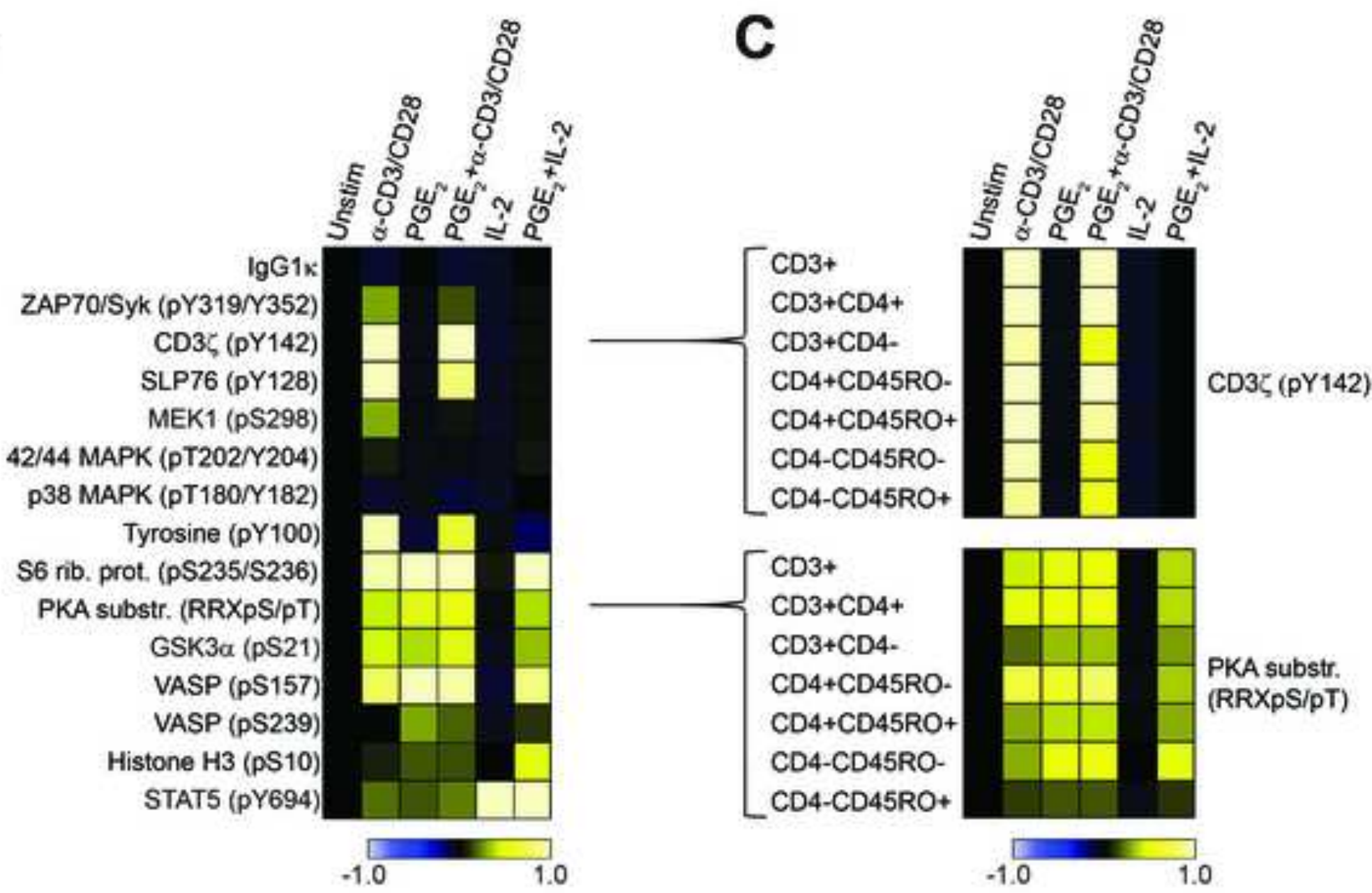


A

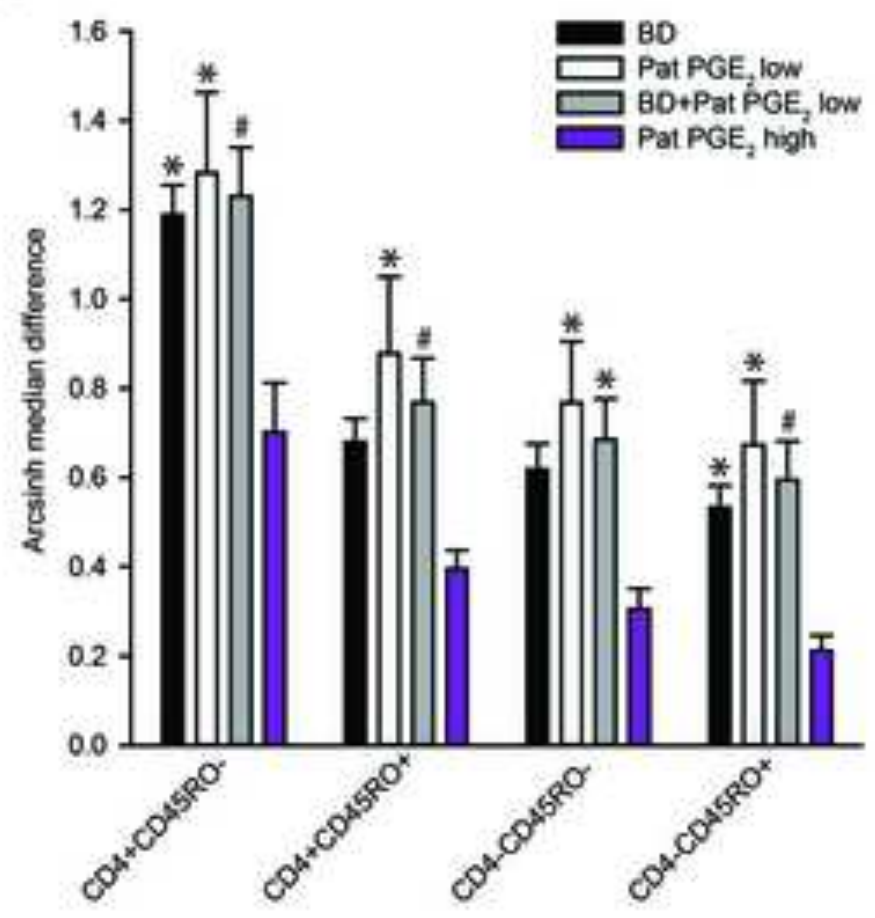

C SLP76 (pY128) phosphorylation

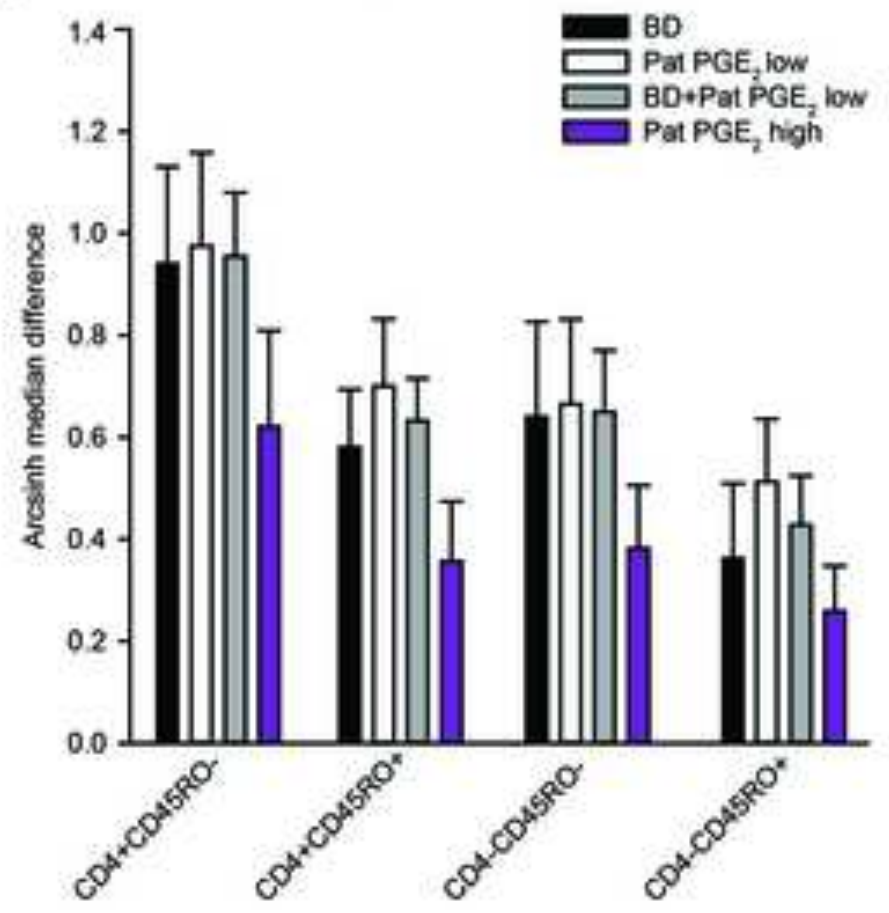

B Reduction in $\mathrm{CD} 3 \zeta$ ( $\mathrm{PY}$ 142) phosphorylation

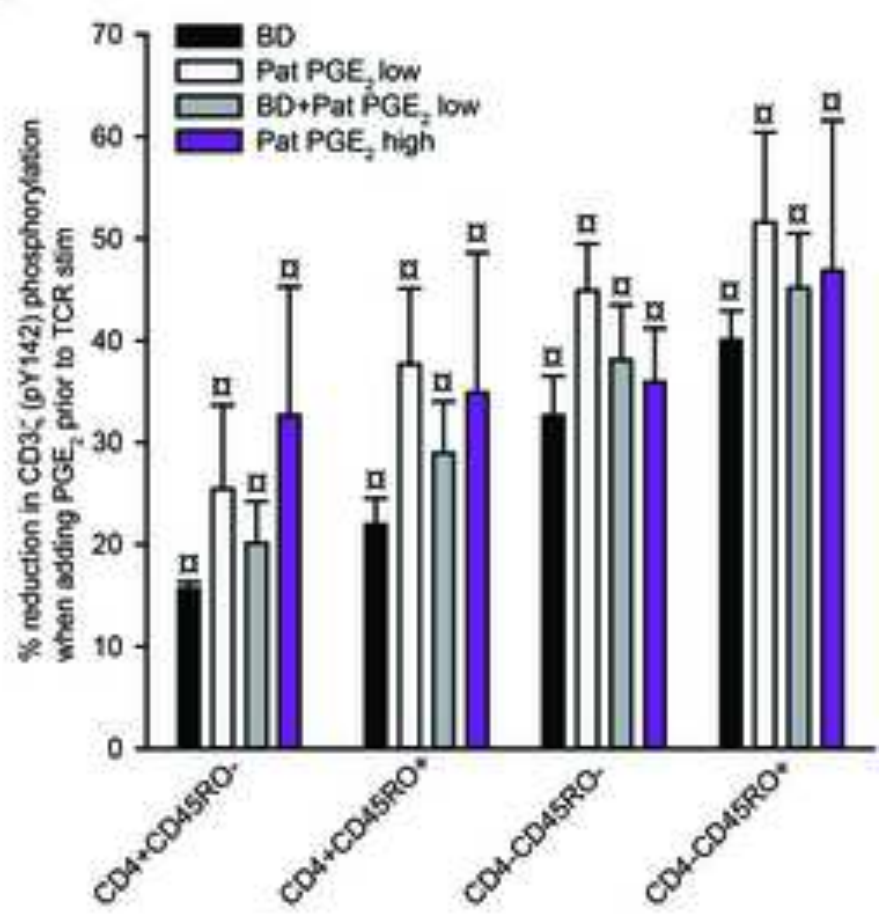


Figure 4

Click here to download high resolution image

A PKA substrate (RRXpSipT) phosphorylation

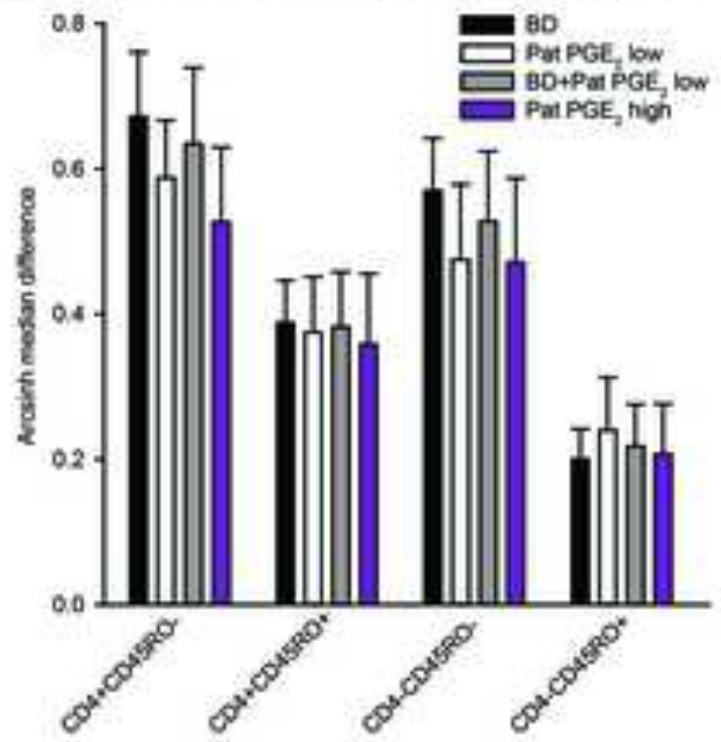

C VASP (pS157) phosphorylation

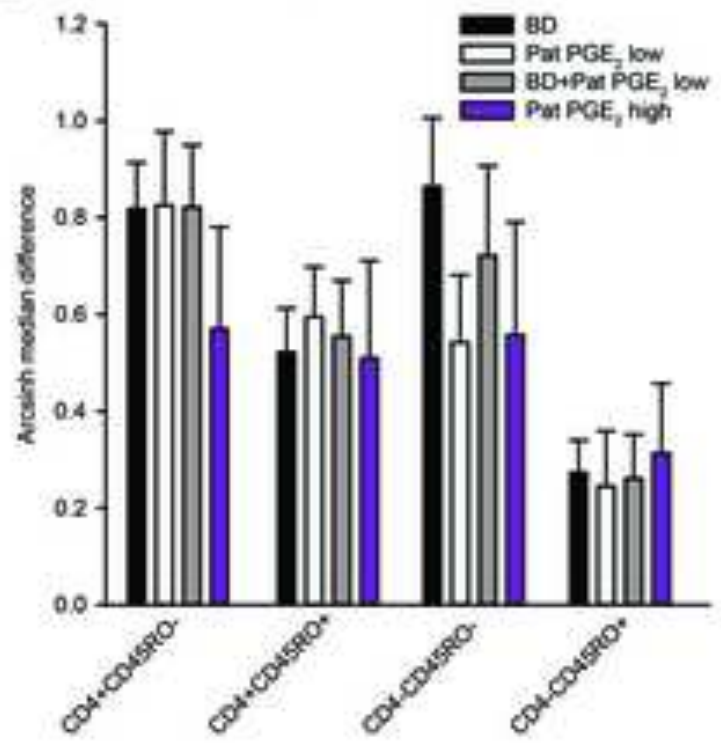

E $\quad$ GSK3 $\alpha(\rho S 21)$ phosphorylation

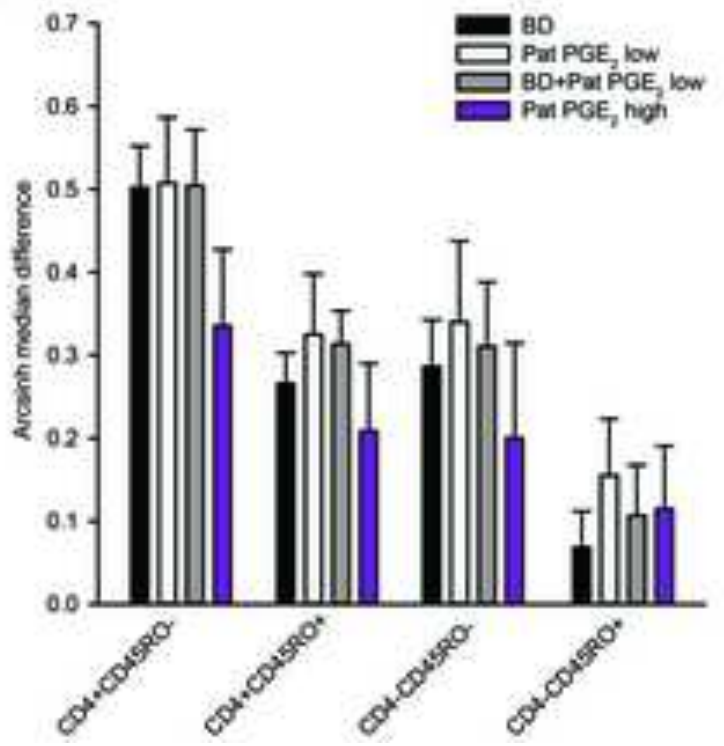

B

Basal levels of PKA substrate (RRXpS/pT) phosphorylation compared to the CD4+CD45RO-population

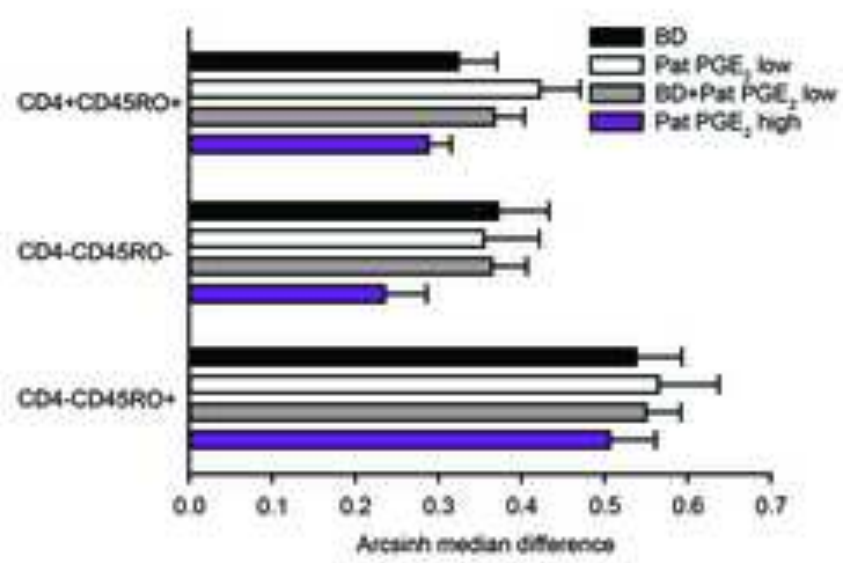

D

Basal levels of VASP (pS157) phosphorylation compared to the CD4+CD4SRO-population

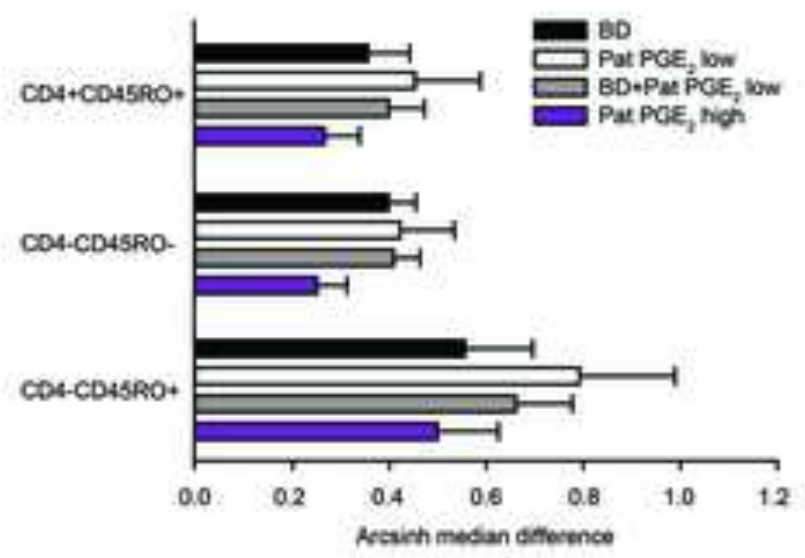

$\mathbf{F}$

Basal levels of GSK3 $\alpha$ (pS21) phosphorylation compared to the CD4+CD45RO- population

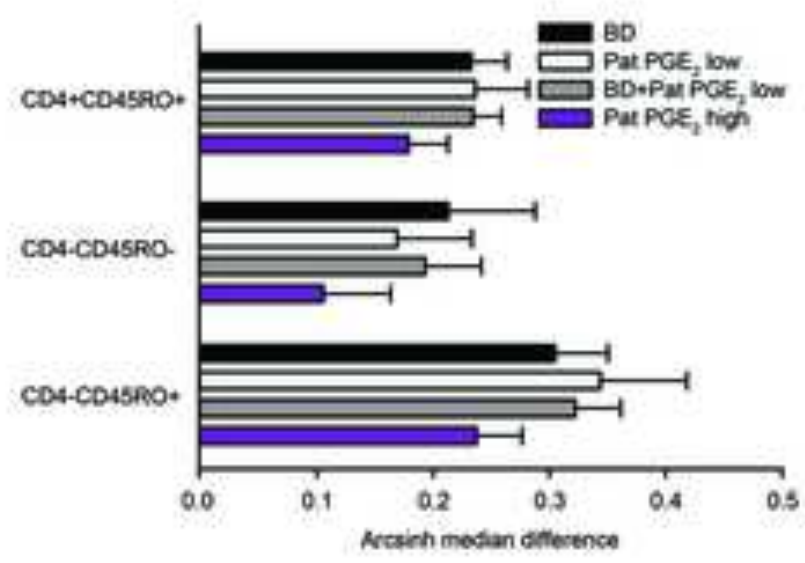


A STAT5 (pY694) phosphorylation

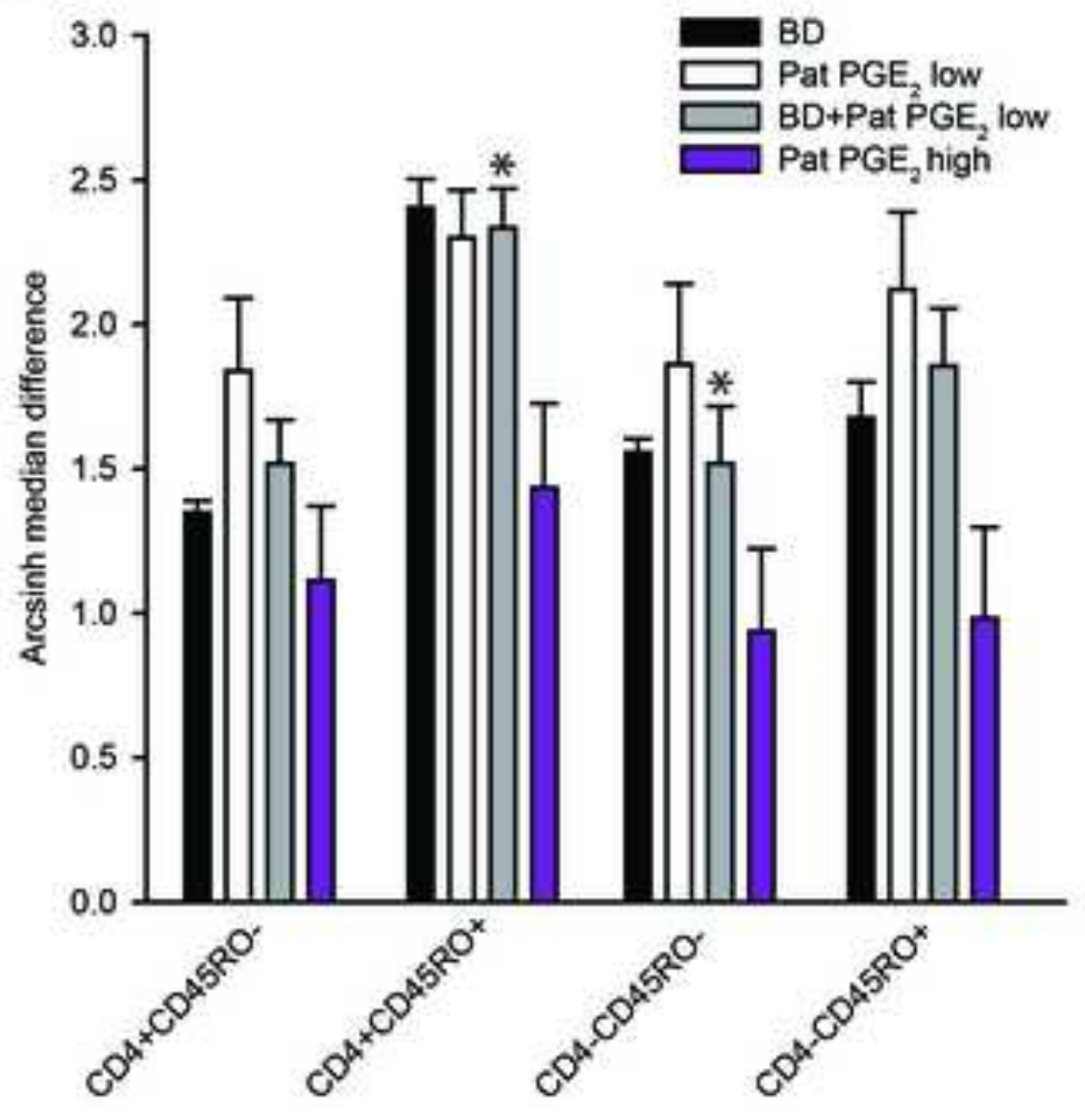

B Basal levels of STAT5 (pY694) phosphorylation compared to the CD4+CD45RO-population

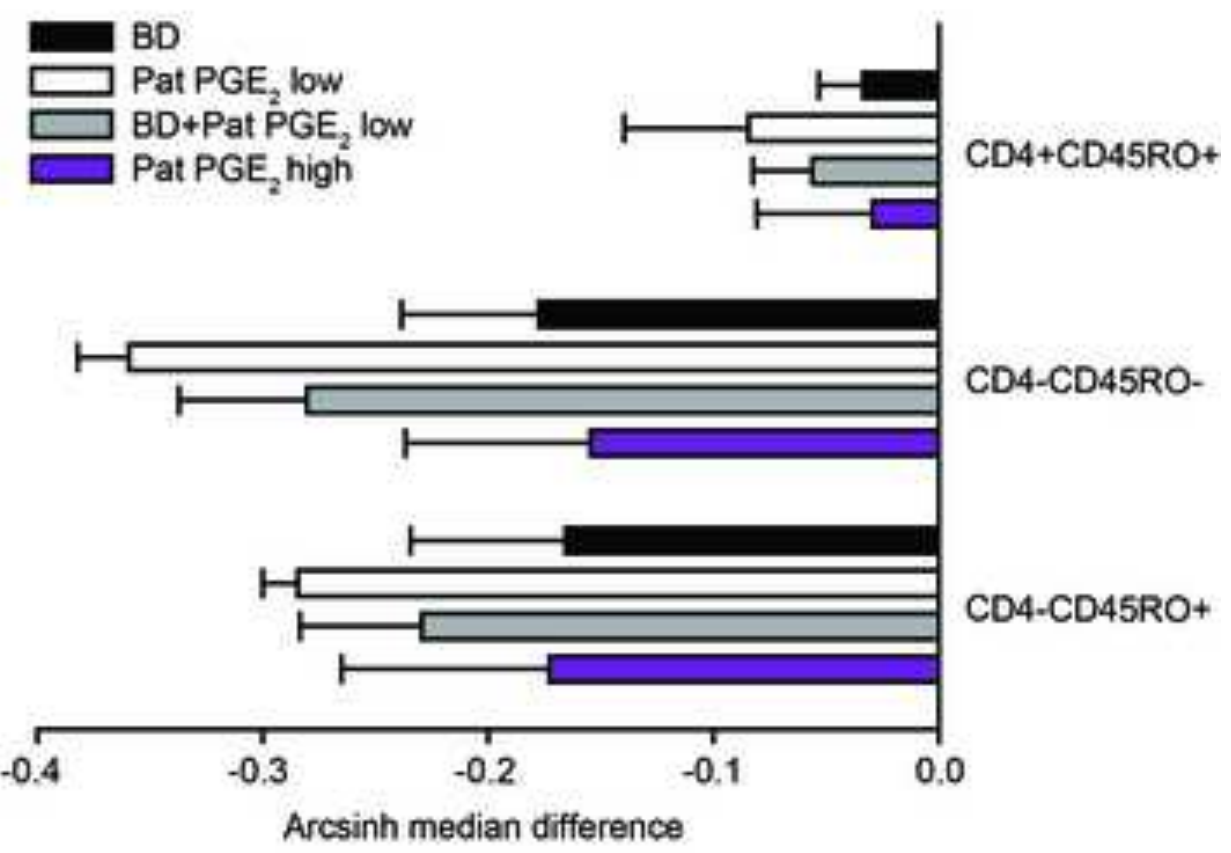

